\title{
Environmental factors associated with overweight among adults in Nigeria
}

\author{
Adewale L Oyeyemi ${ }^{1 *}$, Babatunde O Adegoke ${ }^{2}$, Adetoyeje Y Oyeyemi ${ }^{1}$, Benedicte Deforche ${ }^{3,4}$, \\ Ilse De Bourdeaudhuij ${ }^{4}$ and James F Sallis ${ }^{5}$
}

\begin{abstract}
Background: Understanding environmental factors related to obesity can inform interventions for the world wide obesity epidemic, yet no study has been conducted in this context in Africa. This study examined associations between neighbourhood environment variables and overweight in Nigerian adults.

Methods: A total of 1818 randomly selected residents (age: 20-65 years, 40\% female, 31\% overweight and 61.2\% response) living in high and low socioeconomic (SES) neighbourhoods in Metropolitan Maiduguri, Nigeria, participated in a cross-sectional study. Anthropometric measurements of height and weight and an interviewassisted self-reported measure of 16 items of perceived neighborhood environments were conducted. The primary outcome was overweight (body mass index $[\mathrm{BMI}]>$ or $=25 \mathrm{~kg} / \mathrm{m}^{2}$ ) vs. normal weight $\left(\mathrm{BMl}=18.5-24.9 \mathrm{~kg} / \mathrm{m}^{2}\right)$.

Results: After adjustment for sociodemographic variables, overweight was associated with distant access to commercial facilities (odds ratio [OR], 1.49; 95\% confidence interval [Cl], 1.02- 2.18), poor neighbourhood aesthetics $(\mathrm{OR}, 1.58 ; 95 \% \mathrm{Cl}, 1.16-2.09)$, perceiving garbage and offensive odours in the neighbourhood $(\mathrm{OR}, 1.41 ; 95 \% \mathrm{Cl}, 1.05-$ 1.89) and feeling unsafe from crime at night $(\mathrm{OR}, 1.47 ; 95 \% \mathrm{Cl}, 1.13-1.91)$ and unsafe from traffic $(\mathrm{OR}, 1.56 ; 95 \% \mathrm{Cl}$, 1.17-2.07) in the total sample. Significant interactions regarding overweight were found between gender and four environmental variables, with low residential density $(\mathrm{OR}, 1.39 ; 95 \% \mathrm{Cl}, 1.02-1.93)$ and poorly maintained pedestrian pathways $(\mathrm{OR}, 1.89 ; 95 \% \mathrm{Cl}, 1.13-3.17)$ associated with overweight in men only, and absence of beautiful things $(\mathrm{OR}, 2.23 ; 95 \% \mathrm{Cl}, 1.42-3.50)$ and high traffic making it unsafe to walk $(\mathrm{OR}, 2.39 ; 95 \% \mathrm{Cl}, 1.49-3.83)$ associated with overweight in women only. There were few significant interactions between environmental factors and neighborhood SES regarding overweight.
\end{abstract}

Conclusion: Neighbourhood environment factors were associated with being overweight among Nigerian adults. These findings support previous reports in international literature, but should be replicated in other African studies before any firm conclusions can be drawn.

Keywords: Overweight, Obesity, Neighborhood environment, Africa.

\section{Background}

Overweight and obesity (ie body mass index (BMI) $>25$ $\mathrm{kg} / \mathrm{m}^{2}$ ) are becoming increasingly prevalent worldwide [1-4], and have been associated with adverse health conditions such as hypertension, coronary heart diseases, diabetes, certain forms of cancer and reduced quality of life $[1,5-7]$. The problem of obesity is also rapidly increasing in developing countries with more than 115

\footnotetext{
* Correspondence: alaoyeyemi@yahoo.com

'Department of Physiotherapy, College of Medical Sciences, University of Maiduguri, Maiduguri, Nigeria

Full list of author information is available at the end of the article
}

million people suffering from obesity related problems [8]. The trend in the rising prevalence of obesity and related morbidity and mortality in developing countries has been attributed to rapid urbanization, nutrition transition and reduced physical activity $[1,9,10]$. Prevalence of obesity ranges between $3.3 \%$ and $18.0 \%$ in subSaharan African countries and has become a leading risk factor for cardiovascular diseases (CVD) and diabetes in urban areas of Africa [11]. Chronic diseases which include CVD, stroke, type-2 diabetes, cancer and obesity will by 2020 account for almost three quarters of all deaths worldwide, with $71 \%$ of deaths from CVD

\section{Biomed Central}


and $70 \%$ of deaths from diabetes projected to occur in developing countries $[1,9]$.

Given the current obesity epidemic and its projected consequences, identifying effective population based interventions has become a public health priority in sub-Saharan Africa [11,12]. The problem of obesity is multifactorial, and prevention of weight gain can theoretically be achieved by altering the imbalance between energy consumed and expended $[1,13]$. However, complex behavioural and social factors including environments that promote unhealthy food choices and discourage physical activity are thought to be contributing to the imbalance driving the epidemic of population wide obesity [14-17]. The ecological models based on the principle that health behaviours are influenced by multiple levels, indicate that the environment has a significant effect on diet, physical activity and obesity $[18,19]$. These models have been recommended as a framework for studying health behaviours [20], because they can guide interventions that affect large populations over a long period of time [21]. In this context, the associations between neighbourhood environmental factors and physical activity have been reported in many countries across the continents [22,23], but no study has examined the independent association of environmental variables with overweight and obesity in African countries.

Specific neighbourhood environmental factors and urban sprawl have been associated with overweight and obesity among adults [24-29], and lack of pedestrian amenities, difficult-to-access destinations, poorly-connected street patterns, and neighbourhood safety perceptions have all been hypothesized to contribute to reduced physical activity and development of obesity [30-32]. However, many of these previous studies have been conducted in a few western developed nations, and findings may not apply in the developing countries. To date, research focusing on the relation of the built environment to overweight and obesity has rarely been conducted anywhere in Africa.

Africa-specific studies on the environment-overweight association are needed to guide evidence and develop effective population based interventions that can be tailored to the unique African context. Understanding the environmental factors associated with overweight and obesity among African adults can be critical for establishing the environmental approach as a viable international strategy for obesity control, and could provide clues about how the worldwide epidemic of obesity can be prevented before it becomes strongly established in African countries. The objective of this study was therefore to examine the independent associations of neighbourhood physical activity related environmental variables with overweight among Nigerian adults. This study used self-reported attributes of the neighbourhood environment rather than the objective approach of measuring access to stores, green spaces and food environments.

\section{Methods}

\section{Participants and procedure}

In this cross-sectional study, participants were systematically recruited from 38 neighbourhoods categorized into high and low socioeconomic status (SES) by the ministry of urban planning and development in Maiduguri, Nigeria. Maiduguri is the largest and the capital city in Borno State, North Eastern Nigeria, with an estimated population of 4,151,193 people. According to the 2003 Nigerian Demographic and Health Survey [33], high SES areas are mostly inhabited by people who are gainfully employed (elites), have more than secondary school education, and composed of many houses with functional potable water sources and modern sanitary facilities (flush toilet). Low SES areas mostly have residents who are self- employed (artisans, traders etc.) or unemployed, with varying educational qualifications, and composed of few houses with functional water sources and modern sanitary facilities. For the 1991 population census in Nigeria, a neighbourhood was defined as one or more enumeration areas with a minimum of 50 households [33].

Eleven trained interviewers and the principal investigator recruited participants using a door-to-door strategy. In each neighbourhood, households were enumerated on site and every odd-numbered household was approached for study interest and eligibility. When no one was at home or an eligible adult resided in the household but was not available, the interviewers made a maximum of five return visits for recruitment purposes. Participants who met the eligibility criteria of (1) living within the identified neighbourhoods in the last year, (2) being 20 to 65 years, (3) willing to provide objective weight and height measurements, (4) not being underweight, and (5) being able to complete or understand surveys in either English or Hausa languages were invited to participate in the study.

After recruitment, participants were introduced to the study and their informed consent was obtained. Height and weight was measured using standardized procedures and the questionnaire was self- administered with research staff in attendance to assist participants who had questions about the survey. Among the 2970 individuals contacted for the study, $612(20.6 \%)$ refused participation, 301 (10.1\%) were not eligible, and 2057 (69.3\%) agreed to participate. Among the individuals who agreed to participate, 1818 (88.4\%) provided complete and usable survey information. Age and being underweight were the primary reasons for ineligibility. Response rate 
was $61.2 \%(\mathrm{n}=1818 / 2970)$. All participants provided informed consent, and the study was approved by Human Research Ethic Committee of the University of Maiduguri Teaching Hospital, Nigeria. Data were collected from August 2010 to September 2011.

\section{Measures}

\section{Anthropometry}

Body height and body weight was determined by standard anthropometric methods. Height was measured to the nearest $0.1 \mathrm{~cm}$ in bare feet with participants standing upright against a Holtain portable stadiometer (Crymych, United Kingdom). Weight was measured to the nearest kilogram, with participants lightly dressed using a portable bathroom weighing scale calibrated from 0$120 \mathrm{~kg}$. BMI was calculated as weight $(\mathrm{kg})$ divided by the square of the height $\left(\mathrm{m}^{2}\right)$. The World Health Organization (WHO) principal cutoff points for BMI were used to create the categories: underweight $(<18.5 \mathrm{~kg} /$ $\left.\mathrm{m}^{2}\right)$, normal weight $\left(18.5-<25 \mathrm{~kg} / \mathrm{m}^{2}\right)$, overweight $(25$ $\left.<30 \mathrm{~kg} / \mathrm{m}^{2}\right)$ and obese $\left(>30 \mathrm{~kg} / \mathrm{m}^{2}\right)$ [1]. For present analyses, participants were categorized as normal weight group and overweight group (defined as BMI over 25, including BMI $>30 \mathrm{~kg} / \mathrm{m}^{2}$ ).

\section{Environmental assessment}

An adapted self-administered version of the Physical Activity Neighbourhood Environment Scale (PANES) was used to assess participants' perception of neighbourhood environmental factors. The principal investigator and an expert group (local and international) composed of public health scientists, geographers, town and urban planners, and housing and transportation executives adapted the PANES for use in Nigeria. The 17-item PANES was originally designed by the International Physical Activity Prevalence Study group for brief assessment of variables believed to be related to the activity-friendliness of neighbourhoods [34]. Neighbourhood environmental variables assessed by the adapted PANES included (1) residential density (one question), (2) access to destinations (three questions), (3) connectivity of the street network (one question), (4) infrastructures for physical activity and walking (three items), (4) social environment (one question), (5) aesthetics (three questions), and (6) neighborhood safety (four questions). One item on household motor vehicles was removed from the PANES during the adaptation procedure. With the exception of the question on residential density, all items were phrased as statements about attributes of the neighbourhood, with the following response options: strongly disagree, somewhat disagree, somewhat agree, strongly agree, don't know/not sure or doesn't apply response. For the item on residential density, participants were asked if they perceived their neighbourhood to have many apartments of shared facilities and multiple households or flats of 3 or more stories (high residential density). For the purpose of statistical analysis, a dichotomous variable was constructed. Responses to items were collapsed into two categories: "agree" (strongly agree and somewhat agree) and "disagree" (strongly disagree and somewhat disagree). The PANES has been previously used among Nigerian young adults and showed good reliability [35], comparable with reliability findings among adults in the United States [36] and Sweden [37].

\section{Sociodemographic characteristics}

Information on age, gender, marital status, religion, income, educational level and employment status was elicited from the participants. Marital status was classified as married/ever been married and not married. Educational level was classified as more than secondary school education, secondary school education, and less than secondary school education. Employment status was classified into employed (government/private and self- employed) and unemployed (homemaker, student, retired, or unable to work). Income was categorized into 4 groupings based on NAIRA/month (15 000 NAIRA $\approx$ 100 US Dollars).

\section{Statistical analysis}

Descriptive statistics were computed for all variables. The independent association of perceived environmental variables with overweight as the dependent variable was examined using logistic regression analysis. Adjusted odd ratios (ORs) and 95\% confidence intervals (CI) were calculated for each environmental variable. Interactions between environmental factors and gender regarding overweight were explored by including interaction terms in the regression model. In addition, the interactions of neighborhood SES with environmental variables for overweight were explored, and in case of significant interactions, separate logistic regression analyses were performed in both high and low SES neighborhood. Regression analyses were adjusted for sociodemographic variables (age, gender, neighbourhood location, employment status, and educational level). Income was not included in the regression models due to large number of missing responses $(\mathrm{n}=135)$ and its significant correlation with employment status $(\rho=0.35, \mathrm{p}<0.01)$ and educational level $(\rho=0.51, \mathrm{p}<0.01)$. All statistical analyses were conducted using SPSS version 15 (SPSS. Inc., Chicago, IL).

\section{Results}

A total of 1818 participants comprising $39.9 \%$ women and $60.1 \%$ men, with mean age of $32.3 \pm 10.0$ years and BMI of $24.0 \pm 4.0 \mathrm{~kg} / \mathrm{m}^{2}$, participated in this study. About $31.0 \%$ of the participants were overweight $(22.8 \%$ with BMI $>25 \mathrm{~kg} / \mathrm{m}^{2} ; 8.1 \%$ with BMI $>30 \mathrm{~kg} / \mathrm{m}^{2}$ ). Compared with normal weight participants, overweight 
Table 1 Socio-demographic characteristics and physical activity level of all participants and according to body mass status

\begin{tabular}{|c|c|c|c|c|c|c|c|}
\hline \multirow[t]{3}{*}{ Characteristics } & \multicolumn{2}{|c|}{ Total Sample } & \multicolumn{2}{|c|}{ Normal weight } & \multicolumn{2}{|c|}{ Overweight/Obese } & \multirow[b]{2}{*}{$p$} \\
\hline & \multicolumn{2}{|c|}{$\mathrm{N}=1818$} & \multicolumn{2}{|c|}{$\mathrm{N}=1255(69.0 \%)$} & \multicolumn{2}{|c|}{$\mathrm{N}=563(31.0 \%)$} & \\
\hline & \multicolumn{2}{|c|}{ Mean ( \pm SD) } & \multicolumn{2}{|c|}{ Mean ( \pm SD) } & \multicolumn{2}{|c|}{ Mean ( \pm SD) } & \\
\hline Age (years) & \multicolumn{2}{|c|}{$32.3 \pm 10.0$} & \multicolumn{2}{|c|}{$31.1 \pm 9.9$} & \multicolumn{2}{|c|}{$35.4 \pm 9.9$} & $<0.001 \dagger$ \\
\hline Height (m) & \multicolumn{2}{|c|}{$1.67 \pm 0.07$} & \multicolumn{2}{|c|}{$1.67 \pm 0.1$} & \multicolumn{2}{|c|}{$1.66 \pm 0.1$} & $0.070 \dagger$ \\
\hline Weight (kg) & \multicolumn{2}{|c|}{$66.7 \pm 11.7$} & \multicolumn{2}{|c|}{$61.3 \pm 7.1$} & \multicolumn{2}{|c|}{$78.7 \pm 10.9$} & $<0.001 \dagger$ \\
\hline \multirow[t]{2}{*}{ BMI $\left(\mathrm{Kgm}^{-2}\right)$} & \multicolumn{2}{|c|}{$24.0 \pm 4.0$} & \multicolumn{2}{|c|}{$21.8 \pm 1.8$} & \multicolumn{2}{|c|}{$28.8 \pm 3.4$} & $<0.001 \dagger$ \\
\hline & $\mathrm{N}$ & $\%$ & $\mathrm{~N}$ & $\%$ & $\mathrm{~N}$ & $\%$ & \\
\hline \multicolumn{7}{|l|}{ BMI Prevalence } & $<0.001+\dagger$ \\
\hline Normal weight & 1255 & 69.0 & 1255 & 100 & 0.0 & 0.0 & \\
\hline Overweight & 415 & 22.8 & 0 & 0.0 & 415 & 73.7 & \\
\hline Obese & 148 & 8.1 & 0 & 0.0 & 148 & 26.3 & \\
\hline \multicolumn{8}{|l|}{ Gender } \\
\hline Female & 725 & 39.9 & 480 & 38.3 & 245 & 43.4 & $0.047 \dagger$ \\
\hline Male & 1093 & 60.1 & 774 & 61.7 & 319 & 56.6 & \\
\hline \multicolumn{8}{|l|}{ Marital Status } \\
\hline Married & 1044 & 57.4 & 665 & 53.1 & 428 & 75.9 & $<0.001+\dagger$ \\
\hline Single & 774 & 42.6 & 589 & 47.0 & 136 & 24.1 & \\
\hline \multicolumn{8}{|l|}{ Ethnic group } \\
\hline Hausa/Fulani & 534 & 29.4 & 376 & 30.0 & 158 & 28.0 & $<0.001+\dagger$ \\
\hline Kanui/Shuwa & 619 & 34.0 & 485 & 38.7 & 134 & 23.8 & \\
\hline Others & 665 & 36.6 & 429 & 31.3 & 272 & 48.2 & \\
\hline Educational level & & & & & & & \\
\hline > Secondary School & 533 & 29.3 & 325 & 25.9 & 208 & 36.9 & $<0.001+\dagger$ \\
\hline Secondary School & 736 & 40.5 & 522 & 41.6 & 214 & 37.9 & \\
\hline$<$ Secondary School & 549 & 30.2 & 407 & 32.5 & 142 & 25.2 & \\
\hline Employment status & & & & & & & \\
\hline Employed & 1077 & 59.2 & 726 & 57.9 & 351 & 62.2 & $0.043+\dagger$ \\
\hline Unemployed & 741 & 40.8 & 528 & 42.1 & 213 & 37.7 & \\
\hline Monthly Income (N & & & & & & & \\
\hline$<15000$ & 607 & 36.1 & 454 & 38.7 & 153 & 30.1 & $<0.001+\dagger$ \\
\hline $16000-45000$ & 650 & 38.6 & 466 & 39.7 & 184 & 36.1 & \\
\hline $46000-90000$ & 247 & 14.7 & 159 & 13.5 & 88 & 17.3 & \\
\hline$>90000$ & 179 & 10.6 & 95 & 8.1 & 84 & 16.5 & \\
\hline
\end{tabular}

SD- Standard Deviation

BMI- Body Mass Index

*- Do not add to 1818 due to missing values

$\dagger$ - $\mathrm{p}$-values based on independent $t$-test statistic;

t† - $\mathrm{p}$ value based on Chi-Square statistic

individuals were more likely to be older, women, married or been married, have at least secondary school education, employed and of lower income status (Table 1).

A lower proportion of overweight adults compared with their normal weight counterparts perceived their neighbourhood as having high residential density (32.3\% vs $38.1 \%)$, many non-residential places such as schools, workplaces and hospitals ( $83.7 \%$ vs $88.8 \%$ ), proximal access to public transport $(79.0 \%$ vs $83.9 \%)$ and being safe to bicycle $(76.6 \%$ vs $85.1 \%)$. In addition, a higher proportion of overweight adults compared to normal weight participants perceived their neighbourhood as unsafe from traffic to walk (30.3\% vs $25.1 \%)$. (Not shown in table).

Table 2 showed the independent associations of each neighbourhood environment variable with overweight. After adjustment for sociodemographics, five out of 16 neighbourhood environment variables were significantly associated with overweight. Participants who did not report commercial places such as shops, stores and markets to be within walking distance of their homes were $49 \%$ more likely to be overweight than those who reported proximal facilities $(\mathrm{OR}=1.49 ; \mathrm{CI}=1.02-2.18)$. Participants who did not perceive many beautiful things 
Table 2 Association between perceived neighborhood environment factors and overweight

\begin{tabular}{lll}
\hline & & $\begin{array}{l}\text { Overweight N }=564 \\
(31.0 \%)\end{array}$ \\
\cline { 2 - 3 } $\mathrm{N} \quad \% \quad \begin{array}{l}\text { Adjusted OR } \\
(95 \% \text { C.I) } \dagger\end{array}$ \\
\hline
\end{tabular}

Residential density

Low

High

Access to commercial places

Disagree

Agree

Access to non-residential places

Disagree

Agree

Access to public transport

Disagree

Agree

Presence of recreational

centers

Disagree

Agree

Presence of pedestrian

pathways

Disagree

Agree

Maintenance of pathways

Poor

Good

Presence of beautiful things

Disagree

Agree

Absence of unattended

animals

Disagree

Agree

Absence of garbages and foul

odors

Disagree

Agree

Seeing people active

Disagree

Agree

Connectivity of street

Poor

Good

Traffic safety for bicycling

Not safe

Safe

Traffic safety for walking

Not safe

Safe

Crime Safety during the day

Not safe $\begin{array}{lll}382 & 67.7 & 1.06 \\ (0.83-1.37)\end{array}$

$\begin{array}{lll}182 & 32.3 \quad 1.00\end{array}$

$18933.51 .49(1.02-2.18)^{*}$

$\begin{array}{lll}375 & 66.5 & 1.00\end{array}$

$92 \quad 16.3 \quad 1.02(0.74-1.39)$

$\begin{array}{lll}472 & 83.7 & 1.00\end{array}$

$11921.0 \quad 1.01(0.74-1.40)$

$\begin{array}{lll}445 & 79.0 \quad 1.00\end{array}$

$15928.20 .96(0.68-1.35)$

$405 \quad 71.8 \quad 1.00$

$16729.6 \quad 1.17(0.85-1.62)$

$397 \quad 70.4 \quad 1.00$

$93 \quad 16.5 \quad 1.18(0.77-1.79)$

$471 \quad 83.5 \quad 1.00$

23040.81 .58 (1.16- 2.09)*

$\begin{array}{ll}334 & 59.2 \quad 1.00\end{array}$

$337 \quad 67.0 \quad 1.19(0.89-1.59)$

$\begin{array}{lll}186 & 33.0 \quad 1.00\end{array}$

25945.91 .41 (1.05- 1.89)*

$305 \quad 54.1 \quad 1.00$

$79 \quad 14.0 \quad 0.75(0.52-1.09)$

$485 \quad 86.0 \quad 1.00$

$82 \quad 14.5 \quad 0.78(0.55-1.10)$

$482 \quad 85.5 \quad 1.00$

$132 \quad 23.4 \quad 1.29(0.90-1.87)$

$43276.6 \quad 1.00$

$17130.31 .56(1.17-2.07)^{*}$

$393 \quad 69.7 \quad 1.00$

$11420.2 \quad 0.91(0.66-1.27)$
Table 2 Association between perceived neighborhood environment factors and overweight (Continued)

\begin{tabular}{llll}
\hline Safe & 450 & 79.8 & 1.00 \\
Crime safety at night & & & \\
Not safe & 245 & 43.3 & $\mathbf{1 . 4 7}$ \\
Safe & 319 & 56.6 & 1.00 \\
\hline
\end{tabular}

$\mathrm{Cl}$ indicates confidence intervals; and $\mathrm{OR}$, odds ratio

† Adjusted for age, gender, neighborhood location, marital status, ethnic group, employment status, and educational level

* $P<0.05$

in their neighbourhood were $58 \%$ more likely to be overweight than those who reported many beautiful things $(\mathrm{OR}=1.58$; $\mathrm{CI}=1.16-2.09)$. Similarly, those who perceived their neighbourhood not to be free from garbage and offensive odour were $41 \%$ more likely to be overweight than those who perceived high level of garbage and offensive odour $(\mathrm{OR}=1.41 ; \mathrm{CI}=1.05-1.89)$. Participants who perceived their neighbourhood as unsafe from crime during the night were $47 \%$ more likely to be overweight $(\mathrm{OR}=1.47 ; \mathrm{CI}=1.13-1.91)$, and those who perceived their neighbourhood as unsafe from traffic to walk were $56 \%$ more likely to be overweight $(\mathrm{OR}=1.56$; $\mathrm{CI}=1.17-2.07)$ than those who perceived their neighbourhood as safe.

Significant interactions regarding overweight were found between gender and four of the environmental factors (Table 3). While men would be more likely to be overweight when they perceived low residential density $(\mathrm{OR}=1.39, \mathrm{CI}=1.02-1.93)$ and poorly maintained pedestrian pathways $(\mathrm{OR}=1.89, \mathrm{CI}=1.13-3.17)$, these environmental factors were not related with overweight in women. On the other hand, perceiving no beautiful things in the neigborhood $(\mathrm{OR}=2.23, \mathrm{CI}=1.42-3.50)$ and high traffic making it unsafe to walk $(\mathrm{OR}=2.39, \mathrm{CI}$ $=1.49-3.83$ ) were related with higher levels of overweight in women but not in men. (Not shown in table).

Furthermore, significant interactions for overweight were only found between neighborhood SES and two environmental factors as they related to overweight (Table 3 ). Perception of poor aesthetics was significantly related with higher levels of overweight in adults who reside in low SES Neighborhoods (OR $=1.35, \mathrm{CI}=1.02-1.81)$ but not related to overweight in adults who reside in high SES neighborhoods. However, perception of high crime rate at night making it unsafe to walk was significantly related to higher levels of overweight in adults who resided in high SES neighbourhoods $(\mathrm{OR}=2.36, \mathrm{CI}=1.20$ - 4.64) but not related to overweight in adults who resided in low SES neighbourhoods. (Not shown in table).

\section{Discussion}

The major finding in the present study was that perceptions of five neighbourhood environment variables 
Table 3 Significance of interactions between environmental variables, and gender and neighborhood socioeconomic status by binary logistic model

\begin{tabular}{|c|c|c|c|c|}
\hline & \multicolumn{3}{|c|}{ Overweight } & \\
\hline & \multicolumn{4}{|c|}{ Interaction terms with gender and neighborhood SES } \\
\hline & \multicolumn{2}{|c|}{ Gender } & \multicolumn{2}{|c|}{ Neighborhood SES } \\
\hline & ORt & (95\% C.I) & ORt & $(95 \%$ C.I) \\
\hline Residential density (low) & 1.71 & $(1.02-2.86)^{*}$ & 1.07 & $(0.37-3.12)$ \\
\hline Access to commercial places (Disagree) & 1.42 & $(0.74-2.74)$ & 1.25 & $(0.61-2.58)$ \\
\hline Access to non-residential places (Disagree) & 1.35 & $(0.59-3.04)$ & 0.67 & $(0.28-1.57)$ \\
\hline Access to public transport (Disagree) & 0.95 & $(0.49-1.85)$ & 0.72 & $(0.35-1.51)$ \\
\hline Presence of recreational centers (Disagree) & 0.67 & $(0.33-1.37)$ & 1.98 & $(0.86-4.55)$ \\
\hline Presence of pedestrian pathways (Disagree) & 0.89 & $(0.46-1.75)$ & 1.98 & $(0.92-4.05)$ \\
\hline Maintenance of pathways (Poor) & 3.08 & $(1.26-7.49)^{*}$ & 1.72 & $(0.54-5.49)$ \\
\hline Presence of beautiful things (Disagree) & 1.81 & $(1.05-3.13)^{*}$ & 1.29 & $(1.02-2.86)^{*}$ \\
\hline Absence of unattended animals (Disagree) & 1.23 & $(0.68-2.25)$ & 0.89 & $(0.49-1.65)$ \\
\hline Absence of garbages and foul odors (Disagree) & 0.92 & $(0.49-1.71)$ & 2.12 & $(0.83-5.39)$ \\
\hline Seeing people active (Disagree) & 0.74 & $(0.34-1.58)$ & 0.54 & $(0.19-1.46)$ \\
\hline Connectivity of street (Poor) & 1.79 & $(0.88-3.65)$ & 0.78 & $(0.42-1.83)$ \\
\hline Traffic safety for bicycling (Not safe) & 1.13 & $(0.51-2.55)$ & 0.99 & $(0.45-2.20)$ \\
\hline Traffic safety for walking (Not safe) & 2.19 & $(1.22-3.93)^{*}$ & 1.66 & $(0.87-2.71)$ \\
\hline Crime Safety during the day (Not safe) & 1.08 & $0.55-2.12)$ & 0.66 & $(0.24-1.83)$ \\
\hline Crime safety at night (Not safe) & 1.18 & $(0.69-2.04)$ & 2.35 & $(1.66-4.24)^{*}$ \\
\hline
\end{tabular}

OR_odds ratio' *_ statistically significant $(p<0.05)$

$\dagger_{-}$Adjusted for age, neighborhood location, marital status, ethnic group, employment status, and education

$\dagger_{-}$Adjusted for age, gender, marital status, ethnic group, employment status, and education

unfavorable to physical activity were associated with overweight among African adults. The effect sizes were substantial, with unsupportive environment variables associated with $40 \%$ to $60 \%$ higher risk of overweight. Present findings indicate that neighbourhood environments have robust associations with body mass index status among Nigerian adults. To our knowledge, no study has been published on how neighbourhood environment variables relate to overweight and obesity among adults in any African country.

Consistent with studies in the United States $[28,38]$ and Australia [29], being overweight was associated with perception of commercial facilities such as shops, stores and markets not to be within proximal distance of homes. Because people engaged in more physical activity, particularly walking for transportation, when they perceived proximal rather than distant destinations [22,37], availability of facilities within walking distance can positively impact on energy expenditure which may assist in weight control. Locating commercial facilities within neighbourhoods, termed mixed land use, may therefore be a viable strategy for obesity prevention in Nigeria. The replication of this kind of finding in the developing African continent may also suggest an international relevance of land use-mix access as an important environmental variable that can be manipulated by policy for effective intervention to prevent overweight and obesity.
The environmental attribute associated with the highest likelihood of being overweight was absence of many beautiful things in the neighbourhood. This finding in addition to the association between overweight and perceptions of presence of garbage and offensive odours on most streets in the neighbourhood affirms conclusions from previous findings $[27,28]$. This may suggest an important area for possible interventions because neighbourhoods with favourable aesthetics may encourage individuals to be physically active outdoors to enjoy the scenery. Reviews have found neighbourhood aesthetics to be consistently related to recreational physical activity and walking [39-41]. Ensuring good aesthetic quality of the neighbourhood may be a practical and effective policy for encouraging physical activity and reducing overweight and obesity in African adults.

In this study, a higher proportion of overweight individuals compared to their normal weight counterparts tend to report much traffic in their neighbourhoods' street making it difficult to walk. Heavy traffic has previously been associated with obesity among rural [15] and urban [25] residents in the United States, and residents of a metropolitan city in Australia [29]. Interestingly, another environmental variable on safety; high crime rate at night, was also associated with being overweight in the present study. It can be presumed that individuals who perceived threat from crime would be 
less likely to come outdoors to be physically active, and perceptions of heavy traffic in addition to this, can further compromise the choice of an individual to engage in neighbourhood based physical activity. Making the environments safe from traffic and crime may be particularly important for obesity control, because how people use the environment is thought to be dependent on their perceptions of how safe they feel the environment is [42], and this perception can be closely related to health [43]. It should however be noted that the association of these safety variables with physical activity have been inconsistent as indicated by multiple review [39-41].

Because sex differences in the associations between environment and overweight or obesity have not been studied often, those observed in the present study are of particular interest. Significant interactions regarding overweight were found between gender and four of the environmental factors, supporting a conclusion that different environmental factors may be relevant for obesity prevention among African men and women. This suggests the preferences of both women and men need to be considered in the design of activity-supportive and health-promoting neighborhoods. Poor aesthetics and traffic were related to overweight in women only. While good neighborhood aesthetics have been associated with walking among African young women and men [23], high speed of traffic is an important barrier to physical activity that seem to be specific to women in Nigeria [44]. Plausibly, African women may not engage in physical activity when they perceive their neighborhood as aesthetically unpleasing and dangerous due to high traffic, making them more likely to be overweight.

Also worth noting is that low residential density and poorly maintained pedestrian facilities were not related to overweight in the full sample, but positively related to being overweight in men only. These findings suggest the importance of considering sex-specific environmental interventions for obesity control in Africa. For example, pedestrian facilities may not be important to physical activity behaviours of African women because they may want to avoid other users, especially males that are not related to them. In contrast, African men may prefer to engage in physical activity in densely populated neighbourhoods with pedestrian facilities because of the stimulating and role-model effects of being seen engaging in a health enhancing behaviour. In addition, we found few significant interactions between environmental factors and neighborhood SES regarding overweight, suggesting that associations found between overweight and environmental variables may be similarly important across the entire range of SES.

This study has some important limitations which should be considered when interpreting the findings.
Perceived, as opposed to objective, measures of neighbourhood environments were used. Previous studies have reported limited agreement between perceived and objective measures of neighbourhood characteristics, but it is not known which is more important to overweight and obesity $[28,29]$. The study did not include measures of the food environment, which may be important in explaining obesity. Although adjustment was made for neighborhood SES in the analysis, and the interactions of neighborhood SES with environmental variables for overweight were explored, neighborhood SES variables may cofound the outcome variables in this study, making it difficult to determine the relative influence of neighborhood SES and environmental variables on our findings. In addition, participants were younger on the average and were recruited from a single city, which may compromise environmental variability and limit generalization of findings to other African countries. The cross-sectional design utilized does not allow for causal relationships to be determined. Prospective or quasi- experimental studies are needed to strengthen the evidence of causality in this field. However, given the sparse literature on environmental interventions to prevent and control obesity in Africa, correlation studies such as this can provide leads for researchers and practitioners in planning future work. Strengths of the present study included the objective assessment of BMI and the use of neighbourhood environmental items that were tailored to the African context. The sample was also selected to represent a large range of socioeconomic status similar to the general population in North Eastern Nigeria [33]. This study adds to a growing evidence base of environmental correlates of overweight and makes a unique contribution regarding the African population.

In conclusion, neighbourhood environment factors like access to commercial destinations, neighbourhood aesthetics, and safety from crime and traffic were associated with overweight among Nigerian Adults. Unfavorable attributes were associated with $40 \%$ to $60 \%$ increased risk of obesity, which is substantial. The results suggest that previous findings from developed countries may be applicable in Africa, and interventions focusing on neighbourhood environmental factors can be considered as an important public health agenda in Africa in the current battle against the obesity epidemic. However, given the preliminary nature of this study, it is important to replicate these findings in other African studies before any firm conclusions can be drawn.

\section{Acknowledgements}

The authors wish to thank the research staff for their assistance with data collection. We would also like to thank all the participants that took part in this study. 


\section{Author details}

'Department of Physiotherapy, College of Medical Sciences, University of Maiduguri, Maiduguri, Nigeria. ${ }^{2}$ Department of Physiotherapy, College of Medical Sciences, University of Ibadan, Ibadan, Nigeria. ${ }^{3}$ Department of Biometry and Biomechanics, Faculty of Physical Education and Physiotherapy, Vrije Universiteit Brussels, Brussels, Belgium. ${ }^{4}$ Department of Movement and Sports Sciences, Faculty of Medicine and Health Sciences, Ghent University, Ghent, Belgium. ${ }^{5}$ Department of Family \& Preventive Medicine, University of California, San Diego, USA.

\section{Authors' contributions}

ALO conceived, designed and drafted the manuscript; was responsible for data acquisition, conducted the statistical analysis and interpretation of data. $\mathrm{BOA}$ and $\mathrm{AYO}$ contributed to study design and drafting of the manuscript. $\mathrm{BD}, \mathrm{IDB}$ and JFS participated in the design of the study, interpretation of data and critically revised the drafted manuscript for important intellectual content. All authors read and approved the final manuscript.

\section{Competing interests}

The authors declare that they have no competing interests.

Received: 16 October 2011 Accepted: 27 March 2012

Published: 27 March 2012

\section{References}

1. World Health Organozation: Obesity: Preventing and Managing the Global Epidemic. WHO Technical Report Series 8942000 World Health Organization; 2000 [http://whqlibdoc.who.int/trs/WHO_TRS_894.pdf].

2. Abubakari AR, Lauder W, Agyemang C, Jones M, Kirk A, Bhopal RS: Prevalence and time trends in obesity among adult West African populations: a meta-analysis. Obes Rev 2008, 9:297-311.

3. Ogden CL, Carroll MD, Curtin LR, McDowell MA, Tabak CJ, Flegal KM: Prevalence of overweight and obesity in the United States, 1999-2004. JAMA 2006, 295:1549-1555.

4. Berghofer A, Pischon T, Reinhold T, Apovian CM, Sharma AM, Willich SN: Obesity prevalence from a European perspective: a systematic review. BMC Public Health 2008, 8:200.

5. Calle EE, Kaaks R: Overweight, obesity and cancer: epidemiological evidence and proposed mechanisms. Nat Rev Cancer 2004, 4:579-591.

6. Leo'n-Muñoz LM, Guallar-Castillo'n P, Banegas JR, Gutie'rrez-Fisac JL, Lo'pezGarci'a E, Jime'nez FJ, Rodri'guez-Artalej F: Changes in body weight and health-related quality-of-life in the older adult population. Int Journal Obesity 2005, 29:1385-1391.

7. Kozak AT, Daviglus ML, Chan C, Kiefe Cl, Jacobs DR Jr, Liu K: Relationship of body mass index in young adulthood and health-related quality of life two decades later: the Coronary Artery Risk Development in Young Adults study. Int Journal Obesity 2011, 35:134-141.

8. World Health Organization: Controlling the global obesity epidemic. World Health Organization; 2011 [http://www.who.int/nutrition/topics/ obesity/en/index.html].

9. Misra A, Khurma L: Obesity and the metabolic syndrome in developing countries. J Clin Endocrinol Metab 2008, 93:s9-s30.

10. Kruger HS, Venter CS, Vorster HH, Margetts BM: Physical inactivity is the major determinant of obesity in black women in the North West province, South Africa: The THUSA Study. Nutrition 2002, 18:422-427.

11. World Health Organization: Diseases in the African region: Current situation and perspective. WHO Regional Committee for Africa 2005 Maputo; World Health Organization; 2005.

12. Steyn K, Damasceno A: Lifestyle and related risk factors for chronic diseases. In Disease and Mortality in Sub-Saharan Africa, 2nd edition. Volume 18. Edited by: Jamison DT, Feachem RG, Makgoba MW et al. The World Bank. Washington DC, USA; 2006:247-265.

13. Forgelhom M, Kukkonen-Harjula K: Does physical activity prevent weigh gain- a systematic review. Obes Review 2000, 1:95-111.

14. Hill JO, Peters JC: Environmental contributions to the obesity epidemic. Science 1998, 280:1371-1374.

15. Boehmer TK, Lovegreen SL, Haire-Joshu D, Brownson RC: What constitutes an obesogenic environment in rural communities? Am J Health Promot 2006, 20:411-421.

16. Swinburn B, Gill T, Kumanyika S: Obesity prevention: a proposed framework for translating evidence into action. Obes Rev 2005, 6:23-33.
17. Swinburn B, Egger G, Raza F: Dissecting obesogenic environments: the development and application of a framework for identifying and prioritizing environmental interventions for obesity. Prev Med 1999, 29:563-570.

18. Sallis JF, Owen N, Fisher EB: Ecological models of health behavior. In Health Behavior and Health Education: Theory, Research, and Practice 4th edition. Edited by: Glanz K, Rimer BK, Viswanath K. San Francisco: JosseyBass; 2008:465-486

19. Egger G, Swinburn B: An Ecological approach to the obesity pandemic. BMJ 1997, 315:477-480

20. World Health Assembly 57.17. Global strategy on diet and physical activity. World Health Organization, Geneva 2004.

21. Sallis JF, Cervero R, Ascher WW, Henderson K, Kraft MK, Kerr J: An ecological approach to creating active living communities. Annu Rev Public Health 2006, 27(14):1-14, 26.

22. Sallis JF, Bowles HR, Bauman A, Ainsworth BE, Bull FC, Craig CL, Sjöström M, De Bourdeaudhuij I, Lefevre J, Matsudo V, Matsudo S, Macfarlane DJ, Gomez LF, Inoue S, Murase N, Volbekiene V, McLean G, Carr H, Heggebo LK, Tomten H, Bergman P: Neighborhood environments and physical activity among adults in 11 countries. Am J Prev Med 2009, 36:484-490.

23. Oyeyemi AL, Adegoke BOA, Oyeyemi AY, Sallis JF: Perceived environmental correlates of physical activity and walking in African young adults. Am J Health Promot 2011, 25:e10-e19.

24. Lopez R: Urban sprawl and risk for being overweight or obese. Am J Public Health 2004, 94:1574-1579.

25. Joshu CE, Boehmer TK, Brownson RC, Ewing R: Personal, neighbourhood and urban factors associated with obesity in the United States. $J$ Epidemiol Community Health 2008, 62:202-208.

26. Ewing R, Schmid T, Killingsworth R, Zlot A, Raudenbush S: Relationship between urban sprawl and physical activity, obesity, and morbidity. Am $J$ Health Promot 2003, 18:47-57.

27. Catlin TK, Simoes EJ, Brownson RC: Environmental and policy factors associated with overweight among adults in Missouri. Am J Health Promot 2003, 17:249-258.

28. Boehmer T, Hoehner C, Deshpande A, Brennan Ramirez LK, Brownson RC: Perceived and observed neighborhood indicators of obesity among urban adults. Int J Obesity 2007, 31:968-977.

29. Giles-Corti B, Macintyre S, Clarkson JP, Pikora T, Donovan RJ: Environmental and lifestyle factors associated with overweight and obesity in Perth, Australia. Am J Health Promot 2003, 18:93-102.

30. Giles-Corti B, Giles-Corti R: The relative influence of individual, social and physical environment determinants of physical activity. Soc Sci Med 2002, 54:1793-1812.

31. Craig C, Brownson R, Cragg S, Dunn A: Exploring the effect of the environment on physical activity. A study examining walking to work. Am J Prev Med 2002, 23(2S):36-43.

32. Jandy $S$, Boarnet $M$, Ewing R, Killingsworth R: How the built environment affects physical activity. Views from urban planning. Am J Prev Med 2002, 23(2S):64-73.

33. Commission NP, Demographics N, Survey H: National Population Commission (NPC) [Nigeria] and ORC Macro Maryland: Calverton; 2003, 2004.

34. International Physical Activity Prevalence Study: Self- administered environmental module. 2002 [http://www.rohan.sdsu.edu/faculty/sallis/ IPAQIPS.pdf], Revised November.

35. Oyeyemi AL, Adegoke BOA, Oyeyemi AY, Fatudimu MB: Test- retest reliability of IPAQ environmental module in African Population. Int J Behav Nutr Phys Act 2008, 5:38.

36. Sallis JF, Kerr J, Carlson JA, Norman GJ, Saelens BE, Durant N, Ainsworth BE: Evaluating a brief self-report measure of neighborhood environments for physical activity research and surveillance: Physical activity neighborhood environment scale (PANES). J Phys Act Health 2010, 7:533-540.

37. Alexander A, Bergman P, Hagstromer M, Sjostrom M: IPAQ environmental module; reliability testing. J Public Health 2006, 14:76-80.

38. Blanchard CM, McGannon KR, Spence JC, Rhodes RE, Nehl E, Baker F, Bostwick J: Social ecological correlates of physical activity in normal weight, overweight, and obese individuals. Int Journal Obesity 2005, 29:720-726.

39. Saelens BE, Handy SL: Built environment correlates of walking: a review. Med Sci Sports Exerc 2008, 40(7):550-566. 
40. Owen N, Humpel N, Leslie E, Bauman A, Sallis JF: Understanding environmental influences on walking: review and research agenda. Am J Prev Med 2004, 27:67-76.

41. Humpel N, Owen N, Leslie E, Marshal AL, Bauman AE, Sallis JF: Associations of location and perceived environmental attributes with walking in Neighborhoods. Am J Health Prom 2004, 18:239-242.

42. Lake A, Townshend T: Obesogenic environments: exploring the built and food environments. JRSH 2006, 126:262-267.

43. Frank LD, Sallis JF, Conway TL, Chapman JE, Saelens BE, Bachman W: Many pathways from land use to health: associations between neighborhood walkability and active transportation, body mass index, and air quality. J Am Plann Assoc 2006, 72:75-87.

44. Oyeyemi AL, Adegoke BOA, Sallis JF, Oyeyemi AY: Perceived crime and traffic safety is related to physical activity among adults in Nigeria. Journal of Environmental and Public Health.

doi:10.1186/1479-5868-9-32

Cite this article as: Oyeyemi et al:: Environmental factors associated with overweight among adults in Nigeria. International Journal of Behavioral Nutrition and Physical Activity 2012 9:32.

\section{Submit your next manuscript to BioMed Central} and take full advantage of:

- Convenient online submission

- Thorough peer review

- No space constraints or color figure charges

- Immediate publication on acceptance

- Inclusion in PubMed, CAS, Scopus and Google Scholar

- Research which is freely available for redistribution

Submit your manuscript at www.biomedcentral.com/submit 